\title{
EL PENSAMIENTO COMO RIESGO
}

\author{
Juan Pablo Álvarez C'. \\ Recibido: 15.11.2017 Aceptado: 05.12.2017
}

\begin{abstract}
RESUMEN
H ACER FILOSOFÍA COMO SI JUGÁRAMOS UN JUEGO NO ES LO MISMO que decir que el juego de la filosofía consiste en conocer y respetar las reglas y desarrollar destrezas para lograr un mejor desempeño. El proponemos examinar varios tipos de juegos y mostrar que la reflexión filosófica se enriquece cuando el camino lúdico a seguir se define por su indeterminación y su riesgo.
\end{abstract}

Palabras clave: Juego, Infancia, Caillois, Huizinga, Riesgo

\section{THOUGHT AS RISK}

\begin{abstract}
TMaking philosophy as if we were playing a game is not the same as saying that the game of philosophy consists in knowing and respecting the rules and developing skills in order to make a better performance. The crossing between philosophy and infancy is limited to this idea. We aim at examining several types of games and showing that philosophical reflection is enriched when the ludic path to follow is defined by its indeterminacy and risk.
\end{abstract}

Keywords: Game, Infancy, Caillois, Huizinga, Risk

1 Doctor en Filosofía. Director Centro de Estudios en Filosofía e Infancia Universidad de Valparaíso. Correo juan.alvarez@uv.cl 


\section{1. ¡Todos Juegan!}

El año 1938 el historiador holandés Johan Huizinga publicó Homo Ludens, lo que intentaba hacer era superar y ampliar los alcances de las imágenes convencionales del homo sapiens y el homo faber. Su obra no pretendía convertirse en una mera descripción de los aspectos biológicos, psicológicos o etnográficos involucrados, sino más bien en un estudio del juego como fenómeno cultural, concibiéndolo como una función humana tan esencial como la reflexión y el trabajo. Ahora bien, la dimensión lúdica de la existencia no ha sido capital exclusivo de los humanos, es más bien un estadio de relaciones instaladas con anterioridad a nuestra aparición y cuya atención puede ofrecernos algunas luces interesantes.

Así, desde la antropología evolutiva, como sostiene la chilena Isabel Behncke, casi todas las especies de vertebrados y todos los animales de sangre caliente juegan, pero quienes lo hacen son generalmente los animales inmaduros, es decir, los niños de cada especie, haciendo de esta manera que el juego se transforme en una suerte de preparación para la adultez. No obstante, lo anterior, la ciencia ha llevado a concluir también que aquellos animales que resultan ser más longevos, más inteligentes, los que proporcionalmente tienen el cerebro más grande, mejor memoria y forman lazos más duraderos, esos animales no solo son los que juegan más, de manera más compleja, más sofisticada, sino que además son los que juegan durante toda su vida (Behncke 2012).

El juego, de este modo, presentaría esta dualidad en la cual podemos reconocerlo como un estadio intermedio y fugaz en el camino hacia la adultez o bien podemos considerar que él puede o debe acompañar a lo largo de toda su vida al ser humano, independiente de una edad específica. La tesis de Behncke se encamina sobre la segunda perspectiva y viene a sostener la idea de que el juego cumple una función idéntica a la carta del joker en un juego de cartas. El juego tendría esa función de servir de vínculo entre un contexto determinado y la necesidad de adaptarse a dicho contexto. La carta del joker es la única carta que no posee de antemano un valor predeterminado, sino que puede adquirir cualquier valor en la medida que este valor sirva para adecuar y adaptarse a un resultado deseado. La carta del joker es una 
carta que nunca sabes de antemano cuándo o de qué manera la necesitarás, pero será de acuerdo a un contexto específico cuando mostrará su capacidad adaptativa. La dimensión lúdica de la existencia puede asomar, al menos desde la antropología evolutiva, en momentos que podríamos llamar de adaptación cultural.

Si del juego no podemos decir que sea patrimonio de los seres humanos, al menos podemos decir que los tipos de juegos presentes en la cultura humana adquieren formas y estilos marcadamente diferentes (Caillois 1958) y que pueden ser descritos e identificados.

\section{UNA MIRAdA CUÁdRUPLE DEL JUEGo}

El sociólogo francés Roger Caillois, en los años cincuenta, estudió dicha dimensión de la experiencia humana y concluyó que es posible articular una antropología filosófica lúdica para reconocer cuatro tipos de juego presentes transversalmente en la historia humana. En primer lugar, los juegos de agon, aquellos que son de competencia y cuyo énfasis está puesto en el desarrollo de habilidades y estrategias. Dirá Caillois que este tipo de juego es fruto de "la ambición de triunfar gracias al solo mérito en una competencia reglamentada" (Caillois 1967, 88). Podemos sostener que son el tipo de juegos más relacionado con la vorágine social contemporánea, pues tanto ellos como la sociedad misma, ponen a prueba, incansablemente, las destrezas y habilidades de cada persona-jugador, obligándola a establecer estrategias y optimizaciones racionales de sus técnicas, méritos y demás recursos. Cada movimiento debe estar pensado cuidadosamente y debe obedecer a una lógica, a un sentido preciso y a un resultado esperado.

En segundo lugar, los juegos de mimicry, aquellos que tienen relación con la imitación y el simulacro, vinculado al término griego "mímesis" y del cual Caillois dirá que contribuyen al "gusto por adoptar una personalidad ajena" (Ibídem.). Los juegos de simulacro, que juegan a ser otro, se relacionan con juegos de roles y tienen relación con el actor de teatro o de cine (Holzapfel 2004, 76), con la utilización de máscaras o de diversas personalidades. Caillois reconoce en las culturas arcaicas la 
mejor manifestación de este tipo de juegos. Utilizando tatuajes y máscaras nuestros ancestros jugaban a ser otro, identificándose en los rituales con un animal, un espíritu, un demonio, un dios, etc. Este tipo de juego tiene que ver también, en nuestros días, con la conformación de nuestras identidades personales, de tal manera que jugamos a ser cómo nuestros padres, jugamos a desempeñar labores u oficios que nos parecen significativos, entretenidos, importantes, etc.

Un tercer tipo de juego los llamará juegos de alea, cuyo término latino significa "suerte" y su característica principal es su relación con el azar y el destino. Caillois dirá que se trata de "la renuncia de la voluntad en beneficio de una espera ansiosa y pasiva del fallo del destino" (Ibíd.). Los juegos de alea, como la ruleta o la lotería, representan el único juego en el que se hace intervenir el azar, pero junto con ello, lo divino, el destino, lo trascendente, en lo que no se tiene en cuenta los méritos personales (Holzapfel 2004, 75). Un correlato válido para este tipo de juegos sería el jugar a la adivinación, anticipándose a los resultados y otorgándole a dichos supuestos un carácter de profecía.

Por último, encontramos los juegos de ilinx, que son aquellos juegos que ponen en tensión la vida y la muerte, suscitando una experiencia de límite. Ilinx significa en griego "torbellino", del que deriva a su vez ilingos, "vértigo" (Holzapfel 2004, 74). Los juegos de ilinx son el tipo de juego en los que prácticamente es la propia existencia la que se pone en juego. No habría una relación de exterioridad entre jugador y juego, sino más bien un vínculo indisoluble y confuso. Se trata, por ejemplo, de los juegos circenses, y aunque alguien podría objetar que aquí se trata de un "riesgo calculado", sin embargo, la preparación para el "cálculo justo", suele requerir de una vida entera de abnegación y dedicación (Caillios 1967, 227). Se trata de una experiencia lúdica que se ha fusionado con la vida misma, al menos cuando ocurre en el aislamiento del encierro de una carpa.

Estos cuatro distintos tipos de juego tal vez nunca se presentan por separado, más bien se mezclan, combinan o confunden, generando una sinergia en la cual un juego potencia a otro (Holzapfel 2004). Podemos pasar de un juego estratégico y de habilidades a una experiencia lúdica de vértigo y tensión cuando ambos jugadores están 
empatados y solamente faltan segundos para finalizar el juego; o podemos pasar de un juego de imitación, de simulacro, hacia un juego de alea y de agon, ofreciendo apuestas en torno a cuál de los jugadores-actores desempeñará el mejor rol en el simulacro. Así, aunque a menudo se entrecrucen, al haberlos revisado sintéticamente y por separado, podemos proyectar algunas relaciones posibles para la educación, la filosofía y la práctica reflexiva con niños y jóvenes.

\section{Poner en juego la idea de "formación": Agon y Mimicry}

A partir de la cuádruple distinción de Caillois podríamos realizar un examen detenido de cada una de las lógicas lúdicas detrás de cada tipo de juego y relacionarlas con las lógicas argumentativas de cada tipo de pensamiento. La tesis a revisar sería que tanto juego como pensamiento están relacionados por el modo, interés y énfasis que establecen con la experiencia. Sin embargo, antes de que el pensamiento se ponga en juego, hay una función formativa que predispone al jugador a estar más atento a uno que a otro tipo de juego.

Aun cuando el pensamiento infantil, en tanto experiencia humana, atraviese estos cuatro modos de ponerse en juego, las propuestas educativas tienden a enfatizar algunas por sobre otras. De este modo, es posible hacer, por ejemplo, filosofía con niños desde una perspectiva "agonal" o "agonística", que permita estimular el desarrollo de destrezas, habilidades y competencias que capaciten a los niños y niñas para un buen desempeño y una articulación razonada y coherente en el juego de argumentar y reflexionar.

Si nos detenemos aquí, nos encontramos con la bien conocida propuesta para el desarrollo de habilidades en el pensamiento infantil, el Programa Filosofía para niños de Matthew Lipman. En relación con esto, Lipman ha sostenido lo siguiente: "Puede ser que [los niños] tomen la filosofía como algo no diferente de la diversión y los juegos, sin percatarse de que puede ser tan formativa intelectualmente como cualquier cosa que puedan encontrar en su experiencia escolar" (Lipman 1992, 196) 
Los niños a los cuales Lipman hace alusión, efectivamente pueden considerar la filosofía como un modo de poner en juego ciertas habilidades y destrezas, sin embargo, la dimensión lúdica, desde la perspectiva antropológica propuesta por Caillois, sobrepasa enormemente esta descripción "agonal" propuesta por Lipman.

Tomás Miranda, en un libro que revisa el Proyecto lipmaniano, sostiene: "La argumentación, como cualquier juego, está sometida a unas reglas, cuyo seguimiento es condición para ser considerada una actividad racional" (Miranda 2000,13). Y tiene razón Miranda, pero solamente respecto de un tipo de juego, pues como vimos con Caillois, los juegos de imitación, de suerte y de vértigo no parecen hacer gala de la misma racionalidad que este tipo de competencias sí requiere. De hecho, yendo más allá de lo que ahora podemos detenernos, Holzapfel en su "Crítica de la razón lúdica" sostiene que, para un pensador de la ontología como Heidegger, el juego carece de fundamento, constituyéndose como el fundamento sin fundamento: “¿Por qué juega el niño grande del juego del mundo, ese niño avistado por Heráclito en el aión $\square \square$ Juega porque juega? El $<<$ porque $>>$ se sumerge en el juego. El juego es sin $<<$ por qué $>>$. Juega en tanto que juega. Sigue siendo solo juego: lo más alto y lo más hondo" (Heidegger 1991, 188)

Para Eugen Fink el juego también carece de finalidad (Holzapfel 2004, 80) y para el propio Caillois el juego constituye una actividad de lujo: "Quién tiene hambre, no juega" (Caillois 1967, 21). De este modo, variados pensadores proponen que el juego conlleva un tipo de suspensión del juicio, de la razón suficiente y del razonamiento. No todos los juegos, ciertamente, pero al menos los más creativos.

Hacer filosofía como si jugáramos un juego no es lo mismo que decir que el juego de la filosofía consiste en conocer y respetar las reglas y desarrollar destrezas para lograr un mejor desempeño. Esto puede sostenerse, pero solamente de un pequeño número de juegos que requieren el respeto de sus reglas como el principal fundamento y donde el esfuerzo individual es requisito ineludible: "En el agon, el jugador solo cuenta consigo mismo, se esfuerza y se empeña" (Caillois 1967, 88). 
Ahora bien, es posible considerar también las cosas desde otros ángulos. Y es que el pensamiento en la medida en que es reglamentado o normativizado parece perder potencia, dinamismo y dimensión lúdica; sigue siendo un juego, quizás, pero un juego aburrido, solitario, de esos que a nadie les gusta jugar.

El pensamiento infantil, como, al parecer, cualquier otro pensamiento que quiera mantenerse en estado de alerta, exige una tensión con su imposibilidad, con la latencia de su muerte, de su caída, con el riesgo de no ganar nada, como el caso del sujeto de la cuerda floja, en cuyo juego se pone también su propia vida; o como el del apostador, que en el juego de cartas llega incluso a hipotecar su casa, su seguridad, su estabilidad.

Antes de ir hacia esos tipos de pensamientos, detengámonos un poco en el simulacro, puesto que aquí, "en la mimicry, [el niño] imagina que es otro distinto de sí e inventa un universo ficticio" (Caillois 1967, 88). Podemos pensar que una educación centrada en una lógica lúdica de este tipo es muy beneficiosa para el desarrollo de la creatividad, ofreciendo posibilidades de inventar roles, mundos y nuevos significados. También podemos afirmar que pensando desde la simulación de roles aprenderemos a anticipar problemas, clarificar conceptos o adquirir nuevos vocabularios o sensaciones. Sin embargo, una educación basada en la ejercitación mimética, basada en modelos a seguir e imitar, sean estos modelos de comportamientos o imágenes del pensamiento, lo que hará finalmente es inviabilizar el pensamiento naciente, quitándole potencia y creatividad, marcando los caminos a seguir, imponiendo las reglas de un solo estilo de juego.

En Chile, así como en México, Japón, Portugal, Corea del Sur, Singapur, y casi diez países más, se han instalado, desde el año 1999, unos parques privados recreativos exclusivos para niños y niñas. Se llaman "KidZania: la ciudad de los niños". En estos parques los niños tienen la posibilidad de jugar a ser mayores, desempeñando roles, oficios y profesiones de adultos. Existen bancos y un mecanismo de intercambio equivalente al dinero real. En esta ciudad los niños y niñas juegan a trabajar como trabaja un adulto. KidZania, a través de su página web chilena, define su concepto como "Eduentretención", "que consiste en que los niños jueguen ejerciendo distin- 
tas profesiones $u$ oficios y durante esta actividad entiendan mejor cómo funciona el mundo que los rodea. Adicionalmente, durante este proceso sociabilizan, aprenden sobre trabajo en equipo, a tomar decisiones, adquieren conocimientos sobre los principios básicos de economía y educación cívica, así como a desarrollar la imaginación, fortalecer su autonomía y socializar con otros niños".

Sin negar que efectivamente resulta una experiencia muy entretenida para los niños, una explicación desde la perspectiva lúdica de la existencia humana nos muestra claramente que los niños y niñas están siendo expuestos a un tipo de reglas del juego que son las propias reglas del juego adulto. Los niños y niñas pueden ejercitar su autonomía para elegir los oficios o profesiones que estén disponibles, pero no pueden ejercitar su creatividad con la vestimenta, instrumentos, dinámicas o el dinero que utilizarán; todo ello ya está establecido y constituye las reglas del juego: los principios básicos de la economía y de la educación cívica.

Así también la educación infantil y la no infantil, suele proponer una dimensión de imitación, aunque utilice para ello nuevas formas verbales: recitar, memorizar, evaluar, corregir. En un énfasis en la formación por imitación los peligros están en el establecimiento de modelos y patrones de pensamientos, que guíen y dirijan, a modo de reglas del juego, la dinámica de aprender a pensar. Con los juegos de mimicry, también podemos especializarnos en repetir lo que los adultos hacen, lo que los pensadores pensaron, lo que los profesores esperan de nosotros, etc. Imitamos lo ajeno, descuidamos lo propio.

\section{El riesgo de pensar filosóficamente: Alea e IlinX}

Para culminar esta travesía propuesta por Caillois, queremos detenernos en la dupla alea-ilinx, que, si bien puede aparecer contradictoria a veces, creemos que posee conexiones interesantes de ser pensadas y sobretodo diferencias con las dos versiones anteriormente revisadas. 
...en el alea, [el jugador] cuenta con todo salvo consigo mismo y se abandona a fuerzas que se le escapan; (...) en el ilinx, satisface el deseo de ver estropeados pasajeramente la estabilidad y el equilibrio de su cuerpo, de escapar de la tiranía de su percepción y provocar la derrota de la conciencia. (Caillois 1967, 88).

Los juegos de alea, de suerte y destino, son también juegos en contacto con una dimensión espiritual importante. El que juega y en este caso también el que piensa, asume una relación de dependencia con el universo, con el cosmos, establece un reconocimiento de su impotencia, de su fragilidad y se concibe también disponible y abierto hacia lo incierto e inesperado.

Los juegos de azar y de vértigo, ilinx, son también juegos de pensamiento, cuando el pensamiento se vuelve realmente una experiencia (Larrosa 2011). Y para que el pensamiento se experimente como un juego de los tipos mencionados, se requiere que la educación del pensamiento no la entendamos solamente como una cuestión teórica, como algo que tenga que ver con habilidades para hacer una mejor hermenéutica de los textos, o una mejor apropiación de teorías. Tampoco ayuda si se encamina únicamente en la dirección de lograr una mejor imitación de acciones o ideas futuras, haciendo un ejercicio para alcanzar un resultado posterior que ya tenemos previsto: ciudadanos más democráticos, más inteligentes, etc.

La formación del pensamiento se volverá realmente una experiencia si juega el riesgo de jugar sin reglas, pudiendo en ocasiones desarrollar destrezas, memorizar información relevante, relacionar prácticas y teorías, imitar una perspectiva, repetir un ejercicio, etc., bajo la condición de que cualquiera de estas prácticas haya sido encontrada en el camino trazado por un pensamiento activo y atento, en vez de haber sido la propia práctica la que marcó el rumbo a seguir por el pensamiento.

Una experiencia es algo que siempre viene de afuera, según el análisis de Jorge Larrosa (2011). La palabra experiencia comienza con un “ex", que es el mismo "ex" de lo extraño, del extranjero, del exiliado. De esta manera, una experiencia de pensamiento se inicia con aquello que no soy yo, algo que está fuera o que viene de fuera 
(Larrosa, 2011:14). Esto quiere decir que para que un pensamiento tenga lugar, en nuestra relación con un juego aleatorio, esto no debe depender de mí, pues no se trata de una proyección de mí mismo, de lo que yo ya sé, de lo que yo ya pienso, de lo que yo ya siento, etc. Un pensamiento que juega este juego está atento a la irrupción que el destino o el azar o la suerte han favorecido en ese mismo momento y en ese mismo lugar.

Una experiencia de pensamiento es también algo que, por venir de afuera, por estar afuera, necesariamente no soy yo, exige la presencia de un "otro": “...eso que me pasa tiene que ser otra cosa que yo. No otro yo, u otro como yo, sino otra cosa que yo. Es decir, algo otro, algo completamente otro, radicalmente otro" (Larrosa, Ibíd: 15)

Un encuentro con un radicalmente otro es un encuentro vertiginoso, no es trivial ni programado, requiere una disposición abierta del pensamiento, pero también una disposición para correr los riesgos de un encuentro que podría no salir del todo bien. Del otro no sabemos nada, o muy poco, hay adrenalina y tensión, emoción y ansiedad, quizás terror, un no saber.

Finalmente, porque este encuentro y esta jugada del pensamiento no se trata de encontrarse consigo mismo, sino con un "otro", la experiencia es también inapropiable, ajena:

“...eso que me pasa tiene que ser ajeno a mí, es decir, que no puede ser mío, que no puede ser de mi propiedad, que no puede estar previamente capturado o previamente apropiado ni por mis palabras, ni por mis ideas, ni por mis sentimientos, ni por mi saber, ni por mi poder, ni por mi voluntad, etc.” (Larrosa, Ibídem.)

La educación que, en ocasiones, se pone en juego, como quien hace una apuesta o como quien asume riesgos, se convierte a sí misma en un espacio para que alguna experiencia de pensamiento tenga lugar, para que la presencia del otro, que es a la vez otro pensamiento, otra perspectiva, otra mirada, tenga lugar y afecte a mis propias ideas y las transforme. 
La filosofía vinculada con el pensamiento infantil no puede anticiparse a lo que va a ocurrir cuando el vínculo pensamiento-infancia acontezca, no puede prever medidas o calcular alcances, no puede evaluar, no puede esperar ni controlar un resultado. Se trata de poner el pensamiento en juego, pero un juego en el que es el propio pensamiento el que se juega la vida. Poner el pensamiento en juego debe ser también experimentar un juego riesgoso, una aventura, un no saber cómo se juega: "De hecho el verbo $<<$ experienciar $>>0<<$ experimentar $>>(. .$.$) , se dice, en latín, ex/periri. \mathrm{Y}$ de ese periri viene, en castellano, la palabra $<<$ peligro $>>$ (Ibídem: 17)

Hacer del pensamiento un ejercicio estratégico implica aprender las reglas y desarrollar habilidades para un buen desempeño. El riesgo personal es mínimo. Pensar imitativamente reproduce dinámicas ya probadas por otros, enajena metafóricamente, el riesgo es simbólico. Sin embargo, hacer del pensamiento un juego sin otro límite que la renuncia simbólica y práctica a toda eventual técnica garante del éxito y a toda estrategia probada por otros, es abrazar la suerte y estar disponible para empezar de nuevo, desde cualquier lugar, sin mayor respaldo que una vida afirmada desde lo impredecible.

Una experiencia de pensamiento propio, autónomo, creativo y potente es impredecible y es a la vez riesgosa, como un juego de ilinx. Tomar diariamente una micro no es una experiencia hasta el día en que la micro "casi me mata", pero si la micro "casi me matara" todos los días, entonces esto ya no sería ninguna experiencia. La rutina, lo predecible, anula la experiencia, y pensar las mismas cosas puede volverse una rutina. 


\section{Bibliografía}

Behncke, Isabel. 2012. Audiovisual/Conferencia editada "Los Juegos de Nuestros Primos, los Bonobos". Santiago: Centro de Estudios Públicos.

Caillois, Roger. 1958. Teoría de los juegos. Barcelona: Seix Barral.

Caillois, Roger. 1967. Los juegos y los hombres. México: Fondo de Cultura Económica.

Heidegger, Martín. 1991. La proposición del fundamento. Barcelona: Serbal-Guitard.

Huizinga, Johan. 2001. Homo Ludens. Madrid: Alianza.

Holzapfel, Cristóbal (2003), Crítica de la razón lúdica. Trotta, Madrid

Kohan, Walter. 2007. Infancia, política y pensamiento. Buens Aires: Del Estante.

Lipman, Matthew. 2002. La filosofía en el Aula. Madrid: Ediciones de la Torre.

Larrosa, J., Skliar, C. (compiladores). 2011. Experiencia y alteridad en educación. Rosario: Homo Sapiens Ediciones.

Miranda, Tomás. 2000. El juego de la argumentación. Madrid: Ediciones de la Torre. 